\title{
Improved Control of Apple and Citrus Fruit Decay with a Combination of Candida saitoana and 2-Deoxy-D-Glucose
}

\author{
Ahmed El-Ghaouth, Universite De Nouakchott, Faculte des Sciences et Techniques, Nouakchott, Mauritanie, B.P. \\ 5026; Joseph L. Smilanick, United States Department of Agriculture-Agricultural Research Service (USDA-ARS), \\ Fresno, CA, 93727; and Michael Wisniewski and Charles L. Wilson, USDA-ARS Appalachian Fruit Research \\ Station, Kearneysville, WV, 25430
}

\begin{abstract}
El-Ghaouth, A., Smilanick, J. L., Wisniewski, M., and Wilson, C. L. 2000. Improved control of apple and citrus fruit decay with a combination of Candida saitoana and 2-deoxy-D-glucose. Plant Dis. 84-249-253.

A combination of Candida saitoana with $0.2 \%$ 2-deoxy-D-glucose to control decay of apple, lemon, and orange fruit was evaluated. Growth of $C$. saitoana in vitro was reduced by 2-deoxyD-glucose; however, in apple wounds, the yeast grew as well in the presence of 2-deoxy-D-glucose as in its absence. When applied to fruit wounds before inoculation, the combination of $C$. saitoana with $0.2 \%$ 2-deoxy-D-glucose was more effective in controlling decay of apple, orange, and lemon caused by Botrytis cinerea, Penicillium expansum, and P. digitatum than either C. saitoana or the application of a $0.2 \%$ solution of 2-deoxy-D-glucose alone. Increasing the concentration of 2-deoxy-D-glucose from 0.2 to $0.5 \%$ did not improve control significantly. The combination of $C$. saitoana with $0.2 \%$ 2-deoxy-D-glucose was also effective against infections established up to $24 \mathrm{~h}$ before treatment. When applied within $24 \mathrm{~h}$ after inoculation, the combination of $C$. saitoana with $0.2 \% 2$-deoxy-D-glucose was very effective in controlling blue mold of apple and green mold of orange and lemon. The level of control of green mold was equivalent to imazalil treatment. When either $C$. saitoana or $0.2 \%$ 2-deoxy-D-glucose was applied within $24 \mathrm{~h}$ after inoculation, neither had an effect on disease development on apple, orange, or lemon, and the incidence of decay was similar to the water-treated control.
\end{abstract}

Additional keywords: analog, citrus, gray mold, microbial antagonist

In recent years, there has been an increased interest in the development of microbial biocontrol agents as an alternative to synthetic fungicides for the control of postharvest diseases of fruit $(11,20)$. Antagonistic bacteria and yeasts have been isolated and shown to reduce decay of pome and citrus fruit $(2,3,9,11,13,15)$. Presently, three antagonistic microorganisms, a yeast (Candida oleophila Montrocher) and two strains of a bacterium (Pseudomonas syringae van Hall) are commercially available under the trade names ASPIRE, BIOSAVE-100, and BIOSAVE-110, respectively.

Although antagonistic microorganisms have been shown to protect a variety of fruit, their efficacy under semi-commercial conditions is often lower than chemical control $(5,9)$. In large-scale tests, antagonists often provide a level of control

Corresponding author: C. L. Wilson

E-mail: CWilson@AFRS.ARS.USDA.GOV

Current address of A. El-Ghaouth: USDA-ARS Appalachian Fruit Research Station, 45 Wiltshire Road, Kearneysville, WV 25430.

Accepted for publication 12 November 1999.

Publication no. D-1999-1222-02R

(c) 2000 The American Phytopathological Society equivalent to synthetic fungicides only when combined with low doses of synthetic fungicides $(1,3,5,6)$. Furthermore, currently available antagonistic microorganisms do not appear to be able to control previously established infections and are most effective when applied prior to infection by the pathogen $(9,16,21)$. Most infections on citrus and pome fruit occur through wounds inflicted during harvest and subsequent handling. Eradication of these incipient infections, which often occur within 24 to $48 \mathrm{~h}$ after harvest, is required to achieve an economically sufficient level of disease control. Thus, it has become apparent that alternative methods are needed to overcome the variability in efficacy and augment the effectiveness of microbial antagonists. The biocontrol activity of antagonists can be enhanced by naturally occurring organic and inorganic additives. The addition of $\mathrm{CaCl}_{2}$ was shown to increase the protective effect of some antagonists and greatly reduced the populations of yeasts required to give effective control $(12,14,22)$. Enhancement of the biocontrol activity of antagonists by nitrogenous (L-asparagine and L-proline) and carbohydrate (2-deoxy-D-glucose) compounds was also reported in apple and pear fruit, with a lesser effect on pear fruit $(10,13)$. When applied before inoculation with the pathogen, 2-deoxy-D-glucose was shown to improve biocontrol activity of two antagonists, P. syringae and Sporobomyces roseus (10). The use of 2-deoxy-Dglucose, however, was not evaluated for its ability to control incipient infections that originate $24 \mathrm{~h}$ prior to postharvest treatment with biocontrol products.

The sugar analog 2-deoxy-D-glucose could be a useful additive to antagonistic microorganisms, provided that the antagonist is resistant to its fungicidal action. This analog is known to interfere with the growth of major postharvest pathogens and controls decay of apple and peach fruit, with a marked effect at higher concentrations $(7,8,15)$. Recently, 2-deoxy-D-glucose was found to be compatible with the antagonistic yeast Candida saitoana Nakase et Suzuki (19). Preliminary studies indicated that the efficacy of $C$. saitoana against apple decay was enhanced markedly by combining the antagonist with $0.2 \%$ (wt/vol) 2-deoxy-D-glucose.

This investigation was undertaken to assess the potential of 2-deoxy-D-glucose as an additive to enhance the efficacy of $C$. saitoana and to determine whether or not this compound by itself, or in combination with $C$. saitoana, could have an impact on previously established infections (curative activity). The lack of a curative activity has been identified as a major limitation of biocontrol antagonists for postharvest diseases (21).

\section{MATERIALS AND METHODS}

Reagents, microorganisms, and fruit material. The sugar analog 2-deoxy-Dglucose was purchased from Sigma Chemical Co. (St. Louis). Imazalil (44\% a.i., Bromozil 50) was obtained from Janssen Pharmaceutical (Titusville, NJ). Isolates of Penicillium expansum Link, $P$. digitatum (Pers.:Fr.) Sacc., and Botrytis cinerea Pers.:Fr. were obtained from infected fruit and maintained on potato dextrose agar (PDA). A spore suspension was obtained by flooding 2-week-old PDA cultures of $B$. cinerea, $P$. digitatum, and $P$. expansum with sterile distilled water containing $0.1 \%$ (vol/vol) Tween 80 . Spores were counted with a hemacytometer, and spore concentrations of the pathogens were adjusted with sterile distilled water to obtain $10^{6}$ spores $/ \mathrm{ml}$ of $B$. cinerea and $10^{4}$ spores $/ \mathrm{ml}$ of $P$. digitatum and $P$. expansum. C. saitoana was grown at $24^{\circ} \mathrm{C}$ for $48 \mathrm{~h}$ in 
shake-flask cultures of nutrient-yeast broth (NYB). Yeast cells were pelleted by centrifugation with a Sorval RC-58 centrifuge (Dupont Instruments, Wilmington, DE) at $3,000 \times g$ for $20 \mathrm{~min}$, resuspended in sterile distilled water, and centrifuged again. The resulting pellets were dispersed in sterile distilled water containing different concentrations of 2-deoxy-D-glucose and the concentration of the yeast was adjusted to $10^{8} \mathrm{CFU} \mathrm{ml}{ }^{-1}$ using a hemacytometer.

Tree-ripe apple (Malus domestica Borkh.) cv. Red Delicious fruit were handharvested at commercial maturity at the United States Department of AgricultureAgricultural Research Service (USDAARS), Appalachian Fruit Research Station, Kearneysville, West Virginia. The fruit were sorted on the basis of size and the absence of physical injuries or infections and stored at $4{ }^{\circ} \mathrm{C}$ under regular air for 4 months before their use in biocontrol tests. Navel orange cv. Washington (Citrus sinens (L.) Osbeck) and lemon cv. Eureka (Citrus lemon (L.) Burm), grown in the San Joaquin Valley of California, were harvested within 2 days before treatment, washed with water on a processing line, and randomly assigned to treatments.

Effect of 2-deoxy-D-glucose on $C$. saitoana. The effect of different concentrations of 2-deoxy-D-glucose on the survival of $C$. saitoana was determined in 50-ml Erlenmeyer flasks containing $20 \mathrm{ml}$ of $5.0 \%(\mathrm{wt} / \mathrm{vol})$ yeast-maltose broth (YMB). Autoclaved YMB was amended with membrane-sterilized solutions of 2deoxy-D-glucose to obtain concentrations of $0,0.2$, and $0.6 \%$ (wt/vol) 2-deoxy-Dglucose and dispensed immediately into sterile 50-ml Erlenmeyer flasks. Shakeflasks of nutrient-yeast broth medium sup- plemented with 2-deoxy-D-glucose were inoculated with approximately $3.5 \times 10^{5}$ $\mathrm{CFU} \mathrm{ml} \mathrm{m}^{-1}$ of yeast cells and incubated on a rotary shaker at $24^{\circ} \mathrm{C}$ for 5 days. Individual flasks served as one replicate in a randomized complete block design, and four replicates were sampled daily from each treatment. Samples were individually collected and dilution-plated in triplicate on yeastmaltose agar medium. Plates were incubated at $24^{\circ} \mathrm{C}$ and colonies were counted after $48 \mathrm{~h}$ and the results expressed as the mean number of $\mathrm{CFU} \mathrm{ml^{-1 }}$.

The effect of 2-deoxy-D-glucose on the survival of $C$. saitoana was also determined in apple cv. Red Delicious wounds. Apple fruit were wounded ( $3 \mathrm{~mm}$ by $5 \mathrm{~mm}$ deep) once as described previously (14) and fruit wounds were treated with $35 \mu \mathrm{l}$ of a yeast-cell suspension $\left(10^{7} \mathrm{CFU} \mathrm{\textrm {ml } ^ { - 1 }}\right)$ containing 0 or $0.2 \%$ (wt/vol) 2-deoxy-Dglucose. Treated fruit were stored at $24^{\circ} \mathrm{C}$ under high $(95 \%)$ relative humidity $(\mathrm{RH})$ in enclosed plastic trays. Individual fruit served as one replicate in a randomized complete block design, and three replicates were sampled from each treatment at each sampling time. Wound tissue was sampled $0,1,3$, and 7 days after treatment. From each replicate fruit, tissue samples containing the wounds were removed with a number 7 cork borer (6 $\mathrm{mm}$ in diameter), individually homogenized in $5 \mathrm{ml}$ of sterile water, vortexed, dilution-plated in triplicate on a yeast-maltose agar medium, and the plates incubated at $24^{\circ} \mathrm{C}$. Colonies were counted after $48 \mathrm{~h}$ and the results are expressed as the mean number of $\mathrm{CFU}$ per wound.

Biocontrol activity of the combination of 2-deoxy-D-glucose with $C$. saitoana. Experiment 1. The effect of different con-

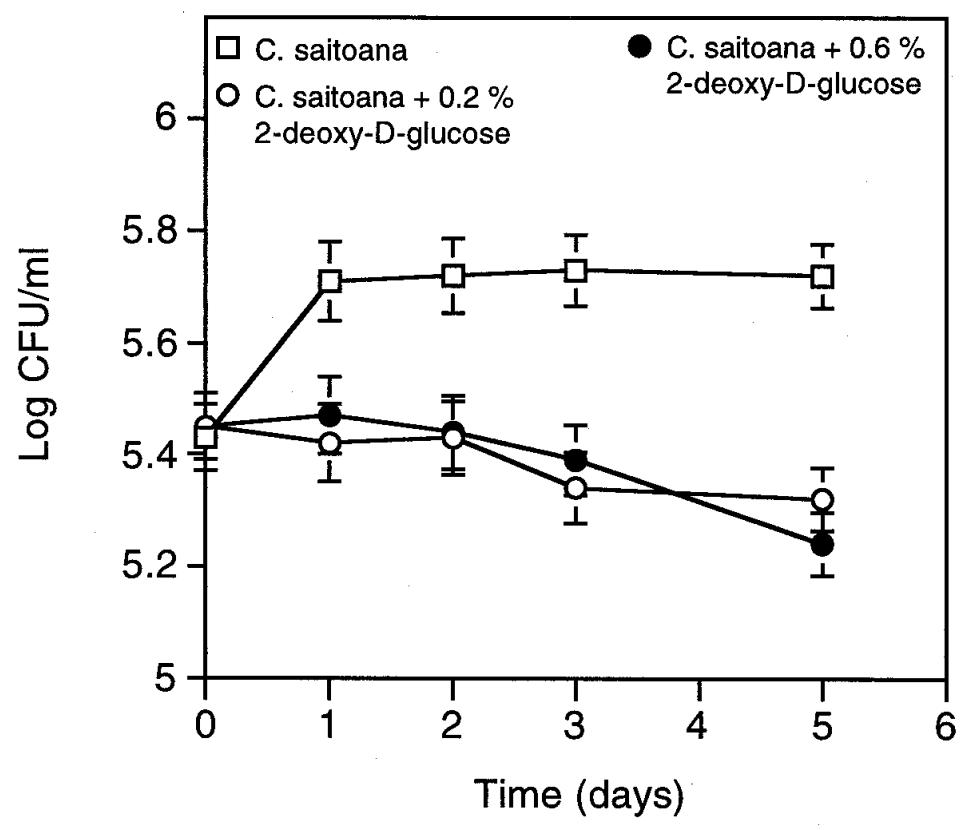

Fig. 1. Population dynamics of Candida saitoana grown in 2-deoxy-D-glucose solutions supplemented with $5.0 \%$ yeast maltose broth. Bars represent standard deviations.

centrations of 2-deoxy-D-glucose on the biocontrol activity of $C$. saitoana was investigated. Apple fruit were wounded as described above. A 35- $\mu$ l drop of a cell suspension of C. saitoana at $10^{8} \mathrm{CFU} \mathrm{ml}^{-1}$ containing $0,0.2$, or $0.6 \%$ (wt/vol) 2-deoxy-D-glucose was placed in each wound and allowed to dry. Within $30 \mathrm{~min}$ of treatment, wounds were challenge-inoculated with $30 \mu \mathrm{l}$ of a conidial suspension of $B$. cinerea or $P$. expansum. Inoculated control fruit were treated with sterile distilled water. Treated fruit were stored at $24^{\circ} \mathrm{C}$ as described above. Each treatment was applied to four replicates of 18 fruit each within each experiment. The entire experiment was repeated twice. Fruit were evaluated daily for symptoms over a period of 14 days. An arcsine transformation was applied to the data prior to analyses of variance. Data from the two experiments were combined because statistical analysis determined there was homogeneity of variances between them. Treatment means were separated by Duncan's multiple-range test $(P=0.05)$.

Experiment 2. The protective and curative effects of the combination of $C$. saitoana with $0.2 \%$ (wt/vol) 2-deoxy-D-glucose on apple cv. Red Delicious inoculated with $P$. expansum, and lemon cv. Eureka and navel orange cv. Washington inoculated with $P$. digitatum, were determined. Apple fruit were wounded once as described above. Lemon and orange fruit were wounded by puncturing each fruit once with a stainless-steel probe with a tip $2 \mathrm{~mm}$ long and $1 \mathrm{~mm}$ wide (17). Wounded fruit were treated with a yeast-cell suspension containing 0 or $0.2 \%$ (wt/vol) 2-deoxy-D-glucose, $0.2 \%$ (wt/vol) 2-deoxy-Dglucose alone, sterile water, or $1,000 \mu \mathrm{g} / \mathrm{ml}$ of imazalil. Only citrus fruit were treated with aqueous solutions of imazalil. Fruit wounds were treated either with the different treatments and then inoculated with a spore suspension of the postharvest pathogen, or inoculated and incubated at $24^{\circ} \mathrm{C}$ for $24 \mathrm{~h}$ before the treatments were applied. Initial observation of hand sections from inoculated controls, collected $24 \mathrm{~h}$ after inoculation with $B$. cinerea, showed that the spores had germinated and that hyphae had ramified throughout the wounded tissue (data not shown).

The different treatments, including the inoculum, were either pipetted directly into apple wounds as described above or applied using a handheld sprayer on citrus fruit. Approximately $0.5 \mathrm{ml}$ was applied to each fruit. Each treatment was applied to four replicates of 18 apples, 60 oranges, or 80 lemons each. The entire experiment was repeated three times. Treated fruit was stored 14 days under high humidity $(95 \%$ $\mathrm{RH}$ ) in enclosed plastic trays at $24^{\circ} \mathrm{C}$, then evaluated for percentage of fruit with lesions. An arcsine transformation was applied to the data prior to analyses of variance. Data from the three experiments 
tion of C. saitoana or $0.2 \%$ 2-deoxy-Dglucose alone, $24 \mathrm{~h}$ after inoculation, had no effect on disease development. After 1 week of storage at $24^{\circ} \mathrm{C}$, the incidence of decay among apple fruit treated with $C$. saitoana, 2-deoxy-D-glucose, and sterile water was above $75 \%$, while only $12 \%$ of the apples treated with the combination of C. saitoana and $0.2 \%$ 2-deoxy-D-glucose were diseased.

Similar control of decay by the combination of $C$. saitoana and $0.2 \%$ 2-deoxy-Dglucose was also observed in lemons and oranges challenged with $P$. digitatum. The application of the combination of $C$. saitoana and $0.2 \%$ 2-deoxy-D-glucose $24 \mathrm{~h}$ after inoculation with $P$. digitatum significantly controlled green mold of lemon and orange. The incidence of green mold among orange and lemon fruit treated with this combination was comparable to that observed after treatment with $1,000 \mathrm{mg} / \mathrm{ml}$ of imazalil (Table 3). The level of decay among fruit treated with either C. saitoana or $0.2 \%$ 2-deoxy-D-glucose alone was not significantly different from the water control.

\section{DISCUSSION}

The biocontrol of postharvest decay of apple by the antagonistic yeast $C$. saitoana and 2-deoxy-D-glucose was reported previously $(7,8)$. In the present study, we demonstrated that the combination of $C$. saitoana with a low dose of $0.2 \%$ 2-deoxy-Dglucose has both protective and curative effects against gray and blue mold of apple and green mold of lemon and orange fruit. The effectiveness on citrus fruit was similar to that of imazalil, a common fungicide with worldwide usage. When applied prior to inoculation with a pathogen, the combination of C. saitoana with $0.2 \%$ 2-deoxyD-glucose was more effective in controlling postharvest diseases of apple, lemon, and orange than either $C$. saitoana or $0.2 \%$ 2-deoxy-D-glucose when used alone. A similar protective effect was also reported in apple and pear fruit treated with a combination of $P$. syringae or Sporobomyces roseus and 2-deoxy-D-glucose when applied before inoculation (10).
Importantly, the combination of $C$. saitoana with $0.2 \%$ 2-deoxy-D-glucose, in addition to having a protective effect, had curative activity against blue and green mold of apple and citrus fruit, respectively, which was comparable to that observed with imazalil. Conversely, C. saitoana and $0.2 \%$ 2-deoxy-D-glucose, when applied alone $24 \mathrm{~h}$ after inoculation, did not inhibit disease development. The curative activity of a combination of $C$. saitoana with 2deoxy-D-glucose represents a substantial improvement over existing microbial biocontrol products. Currently available microbial antagonists confer only a protective effect that diminishes with ripening and provides no control of previously established infections $(16,18,21)$. The inability of antagonists to offer the level of control comparable to synthetic fungicides has been attributed in part to their inability to eradicate incipient infections that occur during and after harvest (1,6,21). Most wound infections of citrus and apple fruit occur during harvesting and subsequent handling; therefore, biological products, in order to be commercially acceptable, must protect wounds and control incipient infections in a manner similar to synthetic fungicides.

Although 2-deoxy-D-glucose is known to interfere with the growth of several filamentous fungi, including major postharvest pathogens $(7,8,15)$, it showed no apparent effect on the growth of $C$. saitoana in wounds. This made it possible to exploit both the antifungal activity of 2deoxy-D-glucose and the antagonistic activity of $C$. saitoana. The enhanced biocontrol activity of the combination of $C$. saitoana and $0.2 \%$ 2-deoxy-D-glucose observed strongly suggests a synergistic effect between $C$. saitoana and 2-deoxy-Dglucose. This was well illustrated by the superior performance of the combination of $C$. saitoana with $0.2 \%$ 2-deoxy-D-glucose in comparison to $C$. saitoana and $0.2 \%$ 2-deoxy-D-glucose alone. By itself, 2-deoxy-D-glucose at a low concentration $(0.2 \% \mathrm{wt} / \mathrm{vol})$ slightly reduced decay. When combined with $C$. saitoana, how-

Table 3. Curative effect of the combination of Candida saitoana with 2-deoxy-D-glucose on decay of apple cv. Red Delicious, navel orange cv. Washington, and lemon cv. Eureka fruit

\begin{tabular}{lccc}
\hline & \multicolumn{3}{c}{${\text { Infected fruit }(\%)^{\mathbf{y}}}$} \\
\cline { 2 - 4 } Treatment $^{\mathbf{z}}$ & Apple & Orange & Lemon \\
\hline Control & $98 \mathrm{a}$ & $100 \mathrm{a}$ & $83 \mathrm{a}$ \\
2-deoxy-D-glucose & $93 \mathrm{a}$ & $87 \mathrm{~b}$ & $81 \mathrm{a}$ \\
C. saitoana & $88 \mathrm{a}$ & $83 \mathrm{~b}$ & $77 \mathrm{a}$ \\
2-deoxy-D-glucose + C. saitoana & $12 \mathrm{~b}$ & $14 \mathrm{c}$ & $11 \mathrm{~b}$ \\
Imazalil $(1,000 \mu \mathrm{g} / \mathrm{ml})$ & $\ldots$ & $9 \mathrm{c}$ & $7 \mathrm{~b}$ \\
\hline
\end{tabular}

${ }^{\mathrm{y}}$ Means are averaged values of three experiments, each containing four replicates of 18 apples, 60 oranges, or 80 lemons each per treatment. Values followed by the same letter are not significantly different at $P=0.05$, according to Duncan's multiple range test.

${ }^{\mathrm{z}}$ Fruit were challenge inoculated with spore suspension of $P$. expansum (apple) or $P$. digitatum (orange and lemon) at $10^{4}$ conidia $\mathrm{ml}^{-1}$ and, $24 \mathrm{~h}$ later, treated with a yeast-cell suspension $\left(10^{8}\right.$ CFU ml ${ }^{-1}$ ) containing 0 or $0.2 \%$ (wt/vol) 2-deoxy-D-glucose, $0.2 \%$ (wt/vol) 2-deoxy-D-glucose alone, imazalil $(1,000 \mu \mathrm{g} / \mathrm{ml}$; orange and lemon only), or sterile water. Decay was evaluated after 7 days of storage at $20^{\circ} \mathrm{C}$.

ever, the inhibitory effect of 2-deoxy-Dglucose was amplified. The antifungal activity of 2-deoxy-D-glucose increases in the absence of carbohydrates (15). The ability of an antagonist to outcompete the pathogen for nutrients $(4,9)$ could result in an increase in the ratio of 2-deoxy-D-glucose to utilizable sugar in the wound site to a level that is inhibitory to the pathogen. This may explain, in part, the observed curative effect of the combination of $C$. saitoana with $0.2 \%$ 2-deoxy-D-glucose.

In conclusion, combining antagonistic yeasts with 2-deoxy-D-glucose can be expected to provide a greater reliability and effectiveness than the approach utilizing biological agents alone.

\section{LITERATURE CITED}

1. Brown, C. E., and Chambers, M. 1996. Evaluation of biological products for the control of postharvest diseases of Florida citrus. Proc. Fla. State. Hortic. Soc. 109:278282.

2. Bull, C. T., Stack, J. P., and Smilanick, J. L. 1997. Pseudomonas syringae strains ESC-10 and ESC-11 survive in wounds on citrus and control green and blue molds of citrus. Biol. Control 8:81-88.

3. Chand-Goyal, T., and Spotts, R. A. 1997. Biological control of postharvest diseases of apple and pear under semi-commercial and commercial conditions using three saprophytic yeasts. Biol. Control 10:199-206.

4. Droby, S., Chalutz, E., Wilson, C. L., and Wisniewski, M. E. 1989. Characterization of the biocontrol activity of Debaryomyces hansenii in the control of Penicillium digitatum on grapefruit. Can. J. Microbiol. 35:794-800.

5. Droby, S., Cohen, A., Weiss, B., Horev, B., Chalutz, E., Katz, H., Keren-Tzur, M., and Shachnai, A. 1998. Commercial testing of Aspire: A yeast preparation for the biological control of postharvest decay of citrus. Biol. Control 12:97-100.

6. Droby, S., Hofstein, R., Wilson, C. L., Wisniewski, M. E., Fridlender, B., Cohen, L., Weiss, B., Daus, A., Timar, D., and Chalutz, E. 1993. Pilot testing of Pichia guilliermondii: A biocontrol agent of postharvest diseases of citrus fruit. Biol. Control 3:47-52.

7. El Ghaouth, A., Wilson, C., and Wisniewski, M. 1995. Sugar analogs as potential fungicides for postharvest pathogens. Plant Dis. 79:254-258.

8. El Ghaouth, A., Wilson, C., and Wisniewski, M. 1997. Antifungal activity of 2-deoxy-Dglucose on Botrytis cinerea, Penicillium expansum, and Rhizopus stolonifer: Ultrastructural and cytochemical aspect. Phytopathology 87:772-779.

9. El Ghaouth, A., Wilson, C., and Wisniewski, M. 1998. Ultrastructural and cytochemical aspect of the biocontrol activity of Candida saitoana in apple fruit. Phytopathology 88:282-291.

10. Janisiewicz, W. J. 1994. Enhancement of biocontrol of blue mold with nutrient analog 2-deoxy-D-glucose on apples and pears. Appl. Environ. Microbiol. 60:2671-2676.

11. Janisiewicz, W. J. 1998. Biocontrol of postharvest diseases of temperate fruits: challenges and opportunities. Pages 171-198 in: Plant-Microbe Interactions and Biological Control. J. Boland and L. D. Kuykendall, eds. Marcel Dekker, Inc., New York.

12. Janisiewicz, W. J., Conway, W. S., Glen, D. M., and Sams, C. E. 1998. Integrating biological control and calcium treatment for controlling postharvest decay of apples. Hort- 
Science 33:105-109.

13. Janisiewicz, W. J., Usall, J., and Bors, B. 1992. Nutritional enhancement of biocontrol of blue mold on apples. Phytopathology 8:1364-1370.

14. McLaughlin, R. J., Wisniewski, M. E., Wilson, C. L., and Chalutz, E. 1990. Effect of inoculum concentration and salt solutions on biological control of postharvest diseases of apple with Candida sp. Phytopathology $80: 456-451$.

15. Moore, D., 1981. Effect of hexose analogs on fungi: Mechanisms of inhibition and resistance. New Phytol. 87:487-515.

16. Roberts, R. G. 1990. Postharvest biological control of gray mold of apple by Cryptococ- cus laurentii. Phytopathology 80:526-530.

17. Smilanick, J. L. 1994. Strategies for the isolation and testing of biological control agents. Pages 25-41 in: Biological Control of Postharvest Diseases of Fruits and VegetablesTheory and Practice. C. Wilson and M. Wisniewski, eds. CRC Press, Boca Raton, FL

18. Smilanick, J. L., Michael, I. F., Mansour, M. F., Mackey, B. E., Margosan, D. A., Flores, D., and Weist, C. F. 1997. Improved control of green mold of citrus with imazalil in warm water compared with its use in wax. Plant Dis. 81:1299-1304.

19. Wilson, C. L., and El Ghaouth, A. 1997. Biological control of postharvest diseases by combining a sugar analog with antagonistic yeast. Patent Serial No. 08/095,552.

20. Wilson, C. L., and Wisniewski, M. E. 1994 Page 182 in: Biological Control of Postharvest Diseases of Fruits and Vegetables-Theory and Practice. CRC Press, Boca Raton, FL.

21. Wilson, C., Wisniewski, M., El Ghaouth, A., Droby, S., and Chalutz, E. 1996. Commercialization of antagonistic yeasts for the biological control of postharvest diseases of fruits and vegetables. J. Indus. Microbiol. Biotechnol. 46:237-242.

22. Wisniewski, M. E., Droby, S., Chalutz, E. and Eilam, Y. 1995. Effect of $\mathrm{Ca}^{+2}$ and $\mathrm{Mg}^{+2}$ on Botrytis cinerea and Penicillium expansum in vitro and on the biocontrol activity of Can dida oleophila. Plant Pathol. 44:1016-1024. 